\title{
ITINERÁRIOS PARA O DESENVOLVIMENTO DA COMPETÊNCIA DOCENTE NA PÓS-GRADUAÇÃO STRICTO SENSU EM ADMINISTRAÇÃO
}

\section{ITINERARIES FOR THE TEACHING COMPETENCE DEVELOPMENT IN POST- GRADUATE STRICTO SENSU IN MANAGEMENT}

\author{
Anielson Barbosa da Silva \\ Universidade Federal da Paraíba \\ anielson@uol.com.br \\ Francisco José da Costa \\ Universidade Federal da Paraíba \\ franzecosta@gmail.com
}

Submissão: 01/08/2013

Aprovação: 11/02/2014

\begin{abstract}
RESUMO
Neste artigo discute-se a formação de docentes de ensino superior e apresenta a indicação de aperfeiçoamentos possíveis na construção de competências para profissionais com nível de formação stricto sensu. O pressuposto foi de que egressos desses cursos precisam desenvolver competências para exercício de atividades de ensino, de pesquisa, de extensão e de desenvolvimento institucional. Foi feita inicialmente uma avaliação global da formação no Brasil, tendo sido identificado um viés de formação na maioria dos programas, por um foco centrado na formação de pesquisadores, implicando uma delegação ao segundo plano, quando muito, da preparação para as demais atividades docentes no ensino superior. A partir dessa constatação, foi explicitada uma proposta de formação de mestres e doutores com base em cinco competências: saberes teóricos (relativa ao conteúdo substantivo de Administração), saberes epistemológicos e metodológicos (para conhecimento do estado da arte e das alternativas de pesquisa em Administração), saberes de ensino (na preparação para a docência), saberes de produção escrita (para diversos gêneros produzidos por um acadêmico) e saberes de prática de pesquisa (para experiência da produção de conhecimentos). É feita a descrição de cada competência e meios possíveis de sua realização.
\end{abstract}

Palavras-Chave: Competência. Docente. Pós-Graduação. Administração. 


\begin{abstract}
This paper discusses the educational model of management stricto sensu level courses, and provides some indications of possible improvements for educational and pedagogical projects. The assumption was that graduates from these courses need to develop skills to engage in teaching, research, extension and community services, and institutional development and management. We did a global evaluation of current education practices in Brazil, and we identified a visible bias in most programs, with a strong focus on the research skill, with a delegation for secondary plan, at best, in the preparation for the other faculty demanded skills'. From this finding, a proposed model for master and doctoral level education was presented and explained. The model is based on five competencies: theoretical knowledge (on the substantive content of management field), epistemological and methodological knowledge (for the comprehension of the state of art and the alternatives for research in management), teaching knowledge (in the preparation for teaching activities), writing knowledge (for various written genres produced by a faculty), and research practice knowledge (to experience of knowledge production). It was made the description of each skill and of possible means of implementation.
\end{abstract}

Key-Words: Competence. Teacher. Post-graduate. Management. 


\section{INTRODUÇÃO}

Este artigo tem por objetivo discutir a formação dos docentes do ensino superior em cursos stricto sensu de mestrado acadêmico e de doutorado. O pressuposto central é de que os cursos de natureza stricto sensu têm por finalidade formar docentes para exercício de atividades correntes exercidas em uma instituição de educação superior, e enfatiza-se aqui a formação para a pesquisa e para o ensino.

Embora se reconheça a relevância de atividades administrativas e de extensão exercida pelos docentes, optou-se por centrar o foco na formação de pesquisa e de ensino, o que, no entendimento dos autores deste artigo, já expande e aperfeiçoa as práticas atuais, que estão centradas de forma evidente na formação para a pesquisa. O pressuposto central é de que os cursos de mestrado acadêmico e de doutorado são o lócus fundamental e especializado da formação de docentes de ensino superior em Administração, e a tendência é que esse modelo (que forma docentes em cursos de mestrado e doutorado) se solidifique na medida em que a pós-graduação em Administração se consolida.

Conforme levantamento empreendido, observa-se que a oferta de cursos de pósgraduação stricto sensu em Administração cresceu significativamente no Brasil. O relatório da avaliação da CAPES para a área de Administração, Ciências Contábeis e Turismo referente aos anos de 2010-2012, cuja avaliação trienal foi realizada em 2013, destacou a existência de 121 programas de pós-graduação recomendados, dos quais 94 são programas da área de Administração, sendo seis de Administração pública (CAPES, 2014).

Em relação ao número de matrículas, em 1998, estas equivaliam a 2.101, e em 2011, aumentaram para 5.392. Ressalta-se que, em 1998, não existia nenhum aluno matriculado em mestrado profissional e, em 2011, o número de matrículas foi de $1.525,28,3 \%$ do total (CIRANI; SILVA; CAMPANARIO, 2012). Não há dúvidas de que a pós-graduação em Administração cresceu e segue a passos largos para uma consolidação nos próximos dez anos.

Para efeito de delimitação desta discussão, firmam-se, nesta introdução, três conceitos centrais: docente, contexto de ação e formação docente. Por docente entende-se o sujeito que exerce atividades de ensino (necessariamente), pesquisa, extensão e desenvolvimento institucional. Aceita-se aqui a docência como uma profissão, em consonância com Tardiff e Lessard (2007), e defende-se que o curso de mestrado é (deve ser) o lócus da formação mais centrada no ensino, e o de doutorado é (deve ser) o lócus da formação de pesquisadores. 
Compreende-se ainda o contexto da ação como o espaço social no qual o docente exerce suas atividades. O espaço central do contexto da ação é a sala de aula universitária, porém, a depender da vocação e da preferência de cada agente, esse espaço ganha a forma de um laboratório de pesquisa, ou mesmo de espaços além das fronteiras da instituição de ensino nas quais se materializam projetos de extensão.

A formação docente é definida como um processo de desenvolvimento de competências que ocorre a partir de situações de aprendizagem que articulam o processo de ensino e de pesquisa como indissociáveis e que merecem atenção pelos agentes responsáveis pelo processo de formação. Considerando-se a natureza pragmática da ação docente, percebese que o processo de formação, tanto na dimensão explícita quanto tácita, é tão mais eficiente o quanto consegue providenciar conhecimento sobre o contexto da ação e o quanto consegue desenvolver uma vivência real desse contexto, de forma reflexiva, crítica e criativa.

Os imperativos da formação profissional no campo da educação em Administração estão mudando em consequência da diversidade de perfis profissionais, dos contextos da formação e também da imprevisibilidade que permeia a ação docente. Isso sinaliza o desafio de construção de modelos de formação. Ainda assim, entende-se ser possível (ao menos pelo que a experiência recente e a visão teórica permitem observar) a delimitação de um bloco de competências centrais, que viabilizam o delineamento de uma hierarquia de competências e de ações de formação possíveis.

Este é o desafio que se toma para este artigo e que se busca implementar em mais três blocos de discussão. Assim, na seção 2 faz-se uma análise global da formação stricto sensu em Administração, a partir da qual se conclui haver algumas limitações nas práticas atuais; na seção 3, expõe-se a proposta de cinco competências centrais; na seção 4 apresentam-se apontamentos à guisa de conclusão e suas implicações teóricas e práticas para a reflexão dos agentes envolvidos na pós-graduação stricto sensu em Administração.

\section{O PROCESSO DE FORMAÇÃO DOCENTE NA PÓS-GRADUAÇÃO STRICTO SENSU EM ADMINISTRAÇÃO}

Considerando-se todo o conjunto de atividades vivenciadas pelos discentes em sua formação, a formação docente pode ser caracterizada como um processo que possui uma dimensão explícita e outra tácita. A dimensão explícita está ligada a um conjunto de 
atividades formais que ocorrem no contexto das disciplinas de conteúdo ou de metodologia dos cursos e que inclui ainda as atividades de orientação mais operacional, como o estágio de docência e os seminários de dissertação ou de tese.

Já a dimensão tácita da formação está ligada à forma como o pós-graduando deve agir no contexto de sua ação profissional. Essa dimensão está intimamente relacionada às práticas sociais e políticas que envolvem a formação de mestres e doutores em Administração, mediada pelos relacionamentos, pelas pressões vivenciadas no decorrer do curso e também pelo acompanhamento recebido no estágio de docência, na produção de artigos, na vivência e na participação de atividades de grupos de pesquisa e na produção dos trabalhos finais (dissertação ou tese).

Conforme argumentam Lima e Riegel (2011), uma dificuldade enfrentada na concepção de formação docente da maioria das instituições brasileiras envolve a dissociação da pesquisa e do ensino no contexto da pós-graduação. A aceitação dessa constatação como uma dificuldade remete a uma questão anterior, a saber: o que significa ser um mestre ou um doutor em Administração? O significado assume perspectivas e orientações diferentes em cada programa de pós-graduação, e uma visão compartilhada depende da difusão de um debate em torno do significado do que é ser docente e de como se dá o processo de formação das competências docentes.

Com efeito, contemporaneamente, não se define mais o professor por sua tarefa de difundir conhecimento. O professor é atualmente visto como um sujeito que gerencia o processo de aprendizagem (inclusive executando o ensino). Segundo Le Boterf (2003, p. 42), "o professor deve tornar-se um profissional capaz de refletir sobre suas práticas, de resolver problemas, de escolher e elaborar estratégias pedagógicas". Levando-se em conta que a maioria dos mestres e doutores vai assumir, após sua formação, a condição de professor nas instituições de educação superior, será que os programas de pós-graduação em Administração estão priorizando a concepção de formação docente nessa perspectiva mais ampla? Ou estão esses programas formando profissionais com competências prioritárias na publicação de artigos e na escrita de uma dissertação de mestrado ou de uma tese de doutorado (que depois rendem mais artigos)?

$\mathrm{Na}$ visão e experiência dos autores deste artigo, a maioria dos programas de pósgraduação em Administração assume uma perspectiva de formação docente mais orientada para a pesquisa e para a produção intelectual, uma vez que os critérios de avaliação dos cursos 
e também dos docentes que solicitam a captação de recursos está vinculada mais à produção intelectual do que com a dimensão da prática de ensino. Embora a formação para a pesquisa seja indiscutivelmente relevante, a sinalização que essa constatação traz é de que a formação de mestres e doutores tem uma deficiência. Concorda-se aqui com Oliveira et al. (2009), quando afirmam que "a formação do docente não deve apenas se concentrar na formação técnica e teórica, mas contribuir para o desempenho didático-pedagógico competente desses docentes no ensino superior".

Nesses termos, precisa-se repensar a formação de mestres e doutores em Administração e incluir nesse processo um conjunto de ações voltadas ao desenvolvimento de competências a partir da adoção de estratégias mediadas pela vivência de experiências no contexto da ação. Naturalmente, tem-se o desafio de definir quais sejam essas competências e, por isso, decidiu-se apresentar uma proposta neste artigo.

Uma reflexão dessa perspectiva poderá contribuir para a solução do problema crônico da formação descompassada. Como indicado na introdução, a formação de mestres e doutores em Administração não é uma atividade marginal de formação, sendo um espaço amplo, dinâmico e em forte crescimento no Brasil nos últimos 15 anos. Ao mesmo tempo em que cresce o número de programas de pós-graduação, amplia-se o contexto de atuação dos docentes, sobretudo em consequência do investimento do governo federal na expansão das Universidades e dos Institutos Federais de Educação, Ciência e Tecnologia e no crescimento das faculdades isoladas. Em alguns desses contextos, há maior procura, sobretudo de mestres, para a atuação em atividades de ensino e, como a maioria dos programas de pós-graduação está direcionada para a formação docente com forte orientação para a pesquisa, vários problemas podem surgir devido a um gap de competências relacionadas à prática de ensino que dificulta o trabalho dos docentes e que demanda das instituições a oferta de programas de formação continuada de professores.

Já em 2004, Pachane e Pereira (2004) questionavam se a formação de mestres e doutores, da forma como vinha sendo realizada, contribuía efetivamente para a melhoria da qualidade didática do ensino superior. Quase uma década após, nota-se que o questionamento continua com uma resposta certamente negativa. Por essa razão, percebe-se que existe a necessidade de uma reflexão permanente por parte dos coordenadores, docentes e discentes dos cursos de pós-graduação em Administração sobre a concepção de formação docente que estão empreendendo, de modo a ampliar o escopo da formação e buscar o equilíbrio entre os 
dois pratos de uma 'balança', que nesse caso é uma metáfora para definir a formação docente, e esse equilíbrio ocorre quando as dimensões do ensino e da pesquisa são colocadas no mesmo nível de relevância pelo curso.

Evidentemente, não seria suficiente apenas mudar a concepção de formação docente, é necessário também refletir sobre as estratégias adotadas pelos docentes dos cursos de pósgraduação para o desenvolvimento de competências de futuros mestres e doutores. Esse é um dos grandes desafios dos cursos, que envolve uma autorreflexão crítica e coletiva sobre o modelo de formação adotado. Outros autores reconhecem isso, como Lima e Riegel (2011), ao destacarem que a realização de ações voltadas para a formação docente que articule as dimensões do ensino e da pesquisa é um desafio para os programas de pós-graduação porque não há evidências de que tal prática esteja consolidada.

Lima e Riegel (2011) ressaltam ainda a dificuldade dos professores em dedicar tempo à formação docente, uma vez que realizam múltiplas responsabilidades (ensino, orientação, pesquisa e publicação, seleção de novos estudantes, entre outros) que podem, eventualmente, reduzir a importância atribuída ao ensino. Outro problema indicado pelos autores envolve o distanciamento de parte dos professores para ações voltadas à prática de ensino, deixando essa responsabilidade ao professor da disciplina específica e voltada para a prática de ensino, além do professor responsável pelo estágio de docência, que em muitos programas é uma atividade obrigatória apenas para os bolsistas.

Pachane e Pereira (2004, p. 5) realçaram a falha no atendimento dessa demanda pela tendência dos programas de pós-graduação de priorizarem as atividades de pesquisa, “tornando-se responsáveis, mesmo que não intencionalmente, por reproduzir e perpetuar a crença de que para ser professor basta conhecer a fundo determinado conteúdo ou, no caso específico do ensino superior, ser um bom pesquisador". Destaca-se ainda que o foco na competência para a pesquisa também é consequência de um processo regulatório de avaliação que valoriza a dimensão da produção intelectual e de projetos de pesquisa.

De fato, uma análise dos critérios adotados pela área para avaliação dos cursos de mestrado e doutorado acadêmico revela que nenhum critério é direcionado para avaliar as ações dos cursos para o desenvolvimento de competências voltadas para a prática de ensino. Ações em sentido contrário já foram propostas, como, por exemplo, o lançamento pela CAPES de um edital (o Pró-Administração de 2008) com o objetivo de financiar projetos de pesquisa voltados para o ensino e a formação do professor na graduação e na pós-graduação. 
Entre as áreas temáticas contempladas pelo edital, destacam-se:

a) Modelos de ensino inovadores e desenhos curriculares na Graduação e PósGraduação;

b) Desenvolvimento de ensino, recursos e tecnologias para uso didático;

c) Formação de professores na pós- graduação e estratégias de educação continuada;

d) Construção e testagem de modelos de ensino de cursos de graduação, especialização, mestrado e doutorado utilizando recursos de pedagogias virtuais e tecnologias de informação e comunicação no ensino presencial e à distância;

e) Criatividade e recursos estéticos em ensino.

O Edital aprovou vinte e dois projetos que estão em fase final de execução e seus resultados estão sendo divulgados nos fóruns de debate dos eventos da ANPAD, bem como em publicações científicas de livros e artigos de periódicos. Tal iniciativa da CAPES é fundamental e deve ser mantida porque estimula os programas de pós-graduação a desenvolverem pesquisas voltadas à melhoria do ensino, mas existe a necessidade de outras ações institucionais voltadas para reflexão sobre a formação docente na pós-graduação.

\section{DESENVOLVIMENTO DE COMPETÊNCIAS DOCENTES NA PÓS-GRADUAÇÃO STRICTO SENSU}

O desenvolvimento da competência docente na Pós-Graduação pode envolver o estabelecimento de trilhas de aprendizagem, que são caminhos alternativos e flexíveis (BRANDÃO, 2012) que subsidiam a formação de uma competência. Também se pode utilizar o conceito de navegação profissional de Le Boterf (2003) para indicar que o profissional em processo de formação deve ter uma "bússola" que o oriente em sua trajetória. Neste artigo, adotou-se o termo 'itinerário' para caracterizar o trajeto a ser percorrido durante um processo de formação que tem como objetivo desenvolver um conjunto de saberes necessários para que o docente integre, mobilize e combine um conjunto de recursos pessoais e do meio em sua ação profissional.

Conforme os requisitos de avaliação, nos projetos de programas de pós-graduação, cada curso estabelece objetivos, perfil do profissional formado e uma ou mais áreas de concentração, que são desdobradas em linhas de pesquisa e disciplinas. A concepção do projeto de um curso de mestrado ou doutorado acadêmico deve ser resultado de uma reflexão 
sobre as bases conceituais que balizam sua concepção, que vão definir o escopo de formação das competências de seus alunos e que são representadas na descrição das áreas de concentração e linhas de pesquisa.

Em boa parte das vezes, a concepção do curso emerge de um agrupamento de projetos de pesquisa e de produção intelectual dos docentes e não de uma concepção de uma base conceitual que dará sustentação à proposta para, posteriormente, definir um corpo docente que esteja alinhado à proposta do curso. A fragilidade dessa construção é superada na medida em que os programas amadurecem, o que tende a acontecer a partir do aperfeiçoamento da articulação do grupo de docentes e da imposição dos agentes de avaliação, que definem critérios de adequação quase sempre seguidos pelos programas.

Por quaisquer das razões, deve-se, acima de tudo, definir qual o objetivo principal do curso de pós-graduação que está sendo concebido em termos de sua vocação para a formação do futuro mestre ou doutor. Idealmente, a orientação para a pesquisa e para o ensino deve estar em sintonia, mas diante das pressões externas e também pela falta de articulação dos docentes em torno de uma proposta mais ampla de formação de uma competência docente, a maioria dos cursos naturalmente conduz seus alunos por uma trilha de aprendizagem mais associada aos saberes teóricos, epistemológicos e metodológicos de prática de pesquisa (inclusive porque, eventualmente, isto é uma forma segura de manter os próprios docentes no circuito de pesquisa em nível nacional e/ou internacional, como a participação em eventos, ou o recebimento de financiamento de projetos por agência de fomento à pesquisa). Não é forte a ênfase nos saberes centrados numa abordagem mais experiencial e de uma aprendizagem baseada na ação mais ampla do trabalho docente que o estudante vivenciará após a conclusão do curso (em especial dos mestres, que terão quase sempre sua atividade docente mais vinculada ao ensino).

Neste artigo, aborda-se o desenvolvimento da competência docente na pós-graduação, considerando-se que essa competência envolve um conjunto de saberes teóricos, epistemológicos e metodológicos, da prática de ensino, de produção escrita e de prática da pesquisa, que, de acordo com o entendimento dos autores deste artigo, precisam ser ofertados pelos programas e mobilizados pelos alunos durante sua formação profissional. A noção de mobilização é proposta por Le Boterf (2003, p. 94) e este destaca que "uma das características essenciais da competência consiste em escolhê-los e combiná-los em relação a objetivos visados (problemas a resolver, projetos a conduzir, atividades a realizar, etc.)". 
O processo de formação profissional não segue um processo linear e estanque, mas sim um processo complexo e dinâmico, inclusive porque sofre a influência do ambiente em que ocorre a aprendizagem. Para contemplar a proposta deste artigo, adota-se a noção de ambiente de aprendizagem preconizada por Merriam e Brockett (2007), que visualizam três dimensões: física, psicológica e social. Ao serem analisadas de forma integrada, as dimensões do ambiente de aprendizagem (física, psicológica e social) podem contribuir significativamente no processo de aprendizagem e na formação da competência docente. (MERRIAM; BROCKETT, 2007).

O ambiente físico é caracterizado pelo espaço onde ocorre a aprendizagem. Pode ser uma sala de aula ou um laboratório, por exemplo, e incorpora aspectos com a temperatura, o barulho e o tamanho do espaço, os recursos tecnológicos disponíveis para condução do processo de aprendizagem, além de incorporar aspectos proxêmicos, que envolvem a maneira como os alunos interagem em termos de linguagem corporal e distância espacial. O ambiente psicológico envolve o clima que se estabelece entre professores e alunos da pós-graduação, uma vez que, quando as relações entre professores e alunos são mediadas pela vivência de experiências de medo, dúvida, pressão, por exemplo, podem interferir de forma positiva ou negativa no processo de aprendizagem. Deve-se criar um ambiente de aprendizagem marcado por um relacionamento de troca e por levar os alunos a se sentirem bem e dispostos a vir para a sala de aula compartilhar experiências, ideias, conceitos e teorias. Já o ambiente social está mais ligado à cultura e aos valores individuais e coletivos, arraigados nos agentes envolvidos e no cenário da aprendizagem e que podem interferir na forma como os alunos vivenciam o curso.

É esperado que um futuro mestre ou doutor em administração, ao concluir o curso, saiba identificar que saberes devem ser mobilizados em sua ação docente a partir de uma concepção de formação que demande a combinação de saberes, e não sua mobilização de forma fragmentada e isolada ou com prioridade centralizada. "O saber combinatório está no centro de todas as competências" (LE BOTERF, 2003, p. 13), e isto é especialmente verdadeiro na pragmática docente em seu contexto de ação.

A Figura 1 mostra cada um dos saberes que integram a formação da competência docente, segundo a visão dos autores deste artigo e com base na literatura pesquisada e nos debates empreendidos entre os autores e outros docentes. Na Figura 1, os hexágonos representam os saberes e são interligados por trapézios que configuram o saber combinatório. 
A combinação das competências estabelece uma arquitetura singular da formação docente, em um processo complexo que possui uma dimensão visível, mais objetiva, e uma invisível, vinculada à subjetividade humana, em alinhamento ao que pensa Rey (2002, p. 27), quando afirma que "a competência ora é concebida como uma potencialidade invisível, interior, pessoal, suscetível de gerar uma infinidade de performances, ora ela se define pelos comportamentos observáveis, exteriores, impessoais".

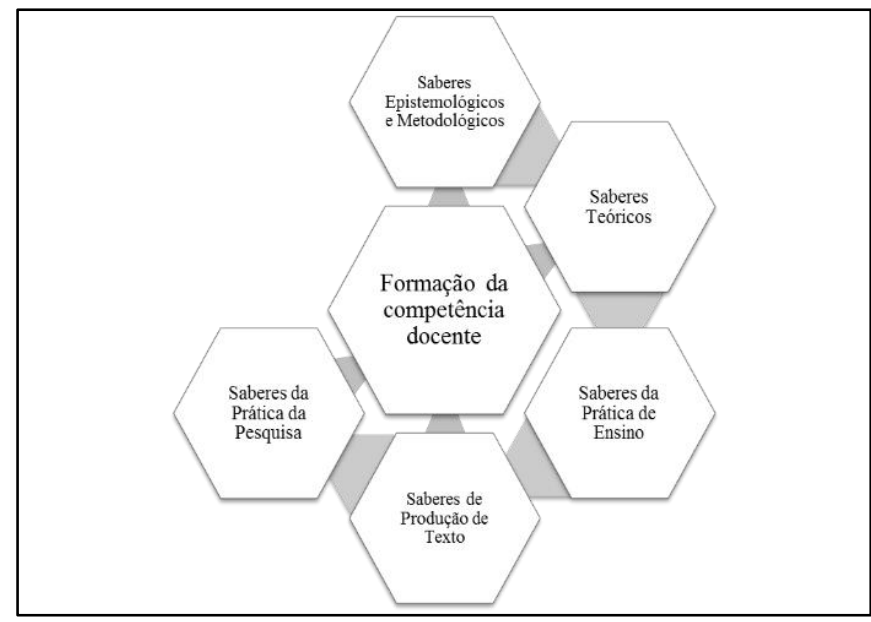

Figura 1 - Saberes necessários à formação docente Fonte: Elaborado pelos autores deste artigo.

Em cada um dos saberes, existem competências mais específicas que ajudam a delimitar ações voltadas para seu desenvolvimento. Para descrever as competências, consideram-se três componentes propostos por Perrenoud (2000, p. 16):

a) os tipos de situações envolvendo um certo domínio;

b) os recursos que se mobilizam, os conhecimentos teóricos ou metodológicos, as atitudes, o savoir-faire e as competências mais específicas;

c) a natureza dos esquemas de pensamento que permitem a solicitação, a mobilização e a orquestração dos recursos pertinentes em uma situação complexa e em tempo real.

Ressalta-se que o terceiro componente é o mais difícil de ser caracterizado, uma vez que os esquemas de pensamento sofrem a influência do ambiente de aprendizagem e também das características dos aprendizes. Sua caracterização demanda a institucionalização de ações de aprendizagem mediadas pela experiência e pela aprendizagem em ação. Os estudos de Villardi e Vergara (2011), Lima e Riegel (2011) e de Oliveira et al. (2009) ratificam a importância de ações de formação centradas na experiência e na ação. 
Antes de apresentar uma descrição dos saberes que integram os itinerários de desenvolvimento da competência docente, faz-se uma breve digressão para justificar o que há de novo, na visão dos autores deste artigo, sobre os saberes necessários à formação docente e de sua pragmática nos cursos de mestrado e doutorado em Administração brasileiros. Por uma visão oriunda da prática destes autores, fundamentada na atuação como professores e em exercícios de coordenação de programas, não se encontrou referencial de concepção ou aplicação estruturado tal como se visualiza (para não fugir do escopo do artigo, que visa mostrar a estruturação de uma proposta, optou-se por não apresentar maiores evidências empíricas, mas estas são facilmente observáveis nos websites dos programas de pósgraduação brasileiros). Na revisão de literatura para fundamentação deste artigo, também não se encontrou qualquer debate com direcionamento equivalente ou mesmo próximo. Ou seja, não se encontrou, na literatura nem por observação, qualquer proposta como a que se defende aqui, o que garante a inovação conceitual da estrutura de referência apresentada a seguir.

Destaca-se ainda que esta proposta pode representar um avanço na discussão sobre o processo de formação docente porque se considera que as dimensões de ensino e pesquisa, no contexto da teoria e da prática da ação docente, devem ser tratadas de forma equilibrada pelos programas de pós-graduação, em uma superação que se entende urgente do modelo de formação com base em pesquisa e produção científica. Não se pretende com esta proposta sugerir um engessamento do processo de formação, mas sim apresentar elementos de uma discussão em torno da elaboração de projetos de cursos a partir de uma base conceitual e experiencial centrada e no reconhecimento da diversidade institucional, cultural, política e social do contexto da formação, respeitando-se a diversidade de áreas de concentração, de linhas de pesquisa e do perfil profissional.

Feita essa digressão, a seguir caracteriza-se cada um dos saberes com destaque para o significado, a justificativa de presença, as competências específicas a serem desenvolvidas e as formas de materialização (atividades de formação).

\subsection{Saberes epistemológicos e metodológicos}

Os saberes epistemológicos e metodológicos estão ligados à análise da administração enquanto campo de produção de conhecimento, com ênfase na compreensão de que tipo de conhecimento é considerado válido a cada perspectiva epistemológica, ao planejamento e à 
aplicação de vertentes filosóficas e correntes científicas que orientam o pesquisador na definição de questões de pesquisa e na escolha de métodos de pesquisa, além dos procedimentos necessários para o planejamento de pesquisas quantitativas e qualitativas, e as estratégias para coleta e análise de material empírico.

A discussão dos saberes epistemológicos e metodológicos em um programa de pósgraduação já geraria um artigo específico considerando-se a relevância dessas duas áreas na formação do docente. Nos programas de pós-graduação da área de Administração, o desenvolvimento de saberes ligados à epistemologia e à metodologia da pesquisa depende da concepção de formação dessa competência no projeto do curso, que se materializa na quantidade de disciplinas obrigatórias e/ou eletivas presentes em cada nível (mestrado ou doutorado), e também da maneira como os docentes responsáveis por essas disciplinas, por meio de estratégias de ensino, orientam a discussão e a reflexão dos conteúdos que integram os planos de ensino.

No doutorado espera-se uma reflexão mais aprofundada sobre a epistemologia na Administração, o que pode acontecer por meio da oferta de uma disciplina obrigatória de 'Epistemologia da pesquisa (ou do conhecimento) em Administração'. Um estudo de Cunha, Reinzman e Silveira (2010), em 22 programas de pós-graduação em Administração que ofertam cursos de doutorado, realizado em 2009, revelou que apenas cinco cursos de doutorado da área ofertavam disciplinas específicas de epistemologia. Certamente, as discussões epistemológicas nos outros cursos eram abordadas em disciplinas de metodologia da pesquisa.

No mestrado, a discussão epistemológica é relevante e deve ser incorporada com o objetivo de levar o mestrando a conhecer os fundamentos que orientam a construção do conhecimento em administração. Porém o desenvolvimento de saberes relacionados à epistemologia na administração é mais essencial nos cursos de doutorado, uma vez que a reflexão sobre a evolução, o processo e o desenvolvimento do conhecimento científico na Administração deve ocupar um lugar de destaque na formação de um doutor na área, sobretudo porque, nesse nível de curso, o objetivo é desenvolver competências que habilitem o egresso do curso a conhecer as vertentes filosóficas e correntes científicas que orientam a produção e difusão do conhecimento científico no(s) campo(s) de Administração.

A dimensão metodológica da formação abrange algumas temáticas centrais, como métodos de pesquisa, tipos de pesquisa, mensuração e desenvolvimento de escalas, design de 
pesquisas quantitativas e qualitativas, estratégias de coleta e análise de material empírico, ética na pesquisa, validade e confiabilidade e métodos de análise (cf. HAIR et al., 2005; PEREIRA, 1997, em sua discussão sobre o processo científico). Ressalta-se que, em vários cursos, temas ligados à epistemologia integram as ementas de disciplinas como Metodologia ou métodos ou Práticas de pesquisa em Administração, o que parece ser uma opção interessante em cursos de mestrado.

A experiência dos autores deste artigo revela a existência de problemas na formação docente no desenvolvimento de saberes epistemológicos e metodológicos em relação ao número de disciplinas que são ofertadas aos alunos, além do perfil do corpo docente responsável pelas disciplinas. Em alguns casos, o professor que tem experiência em pesquisa qualitativa acaba dedicando mais tempo à discussão de métodos e estratégias de coleta e análise de material empírico, relacionados a essa abordagem. Por outro lado, professores com uma orientação funcionalista acabam destacando temas relacionados à formulação de hipóteses, amostragem, design de experimentos, mensuração e análise de dados quantitativos. Outro ponto de destaque envolve os procedimentos normativos para elaboração de projetos de pesquisa e produção de trabalhos acadêmicos, que é foco de alguns docentes.

Nesses casos, o processo de desenvolvimento de uma competência fundamental para a pesquisa acaba não recebendo a devida atenção, prejudicando a formação docente. Para ajudar na delimitação do campo de desenvolvimento dos saberes epistemológicos e metodológicos, definiram-se as seguintes competências específicas para essa dimensão da formação docente:

a) refletir sobre a lógica de construção do conhecimento dentro de cada perspectiva epistemológica;

b) analisar as etapas do processo de construção do conhecimento em administração;

c) conhecer os principais métodos de pesquisa quantitativos e qualitativos;

d) elaborar um projeto de pesquisa dentro de diferentes perspectivas epistemológicas;

e) definir a abordagem metodológica mais adequada à questão de pesquisa;

f) elaborar instrumentos de coleta de material empírico;

g) utilizar estratégias para a coleta e a análise de material empírico;

h) refletir, de forma analítica e critica, sobre a utilização de princípios de ética no processo de pesquisa.

A partir da identificação das competências ligadas aos saberes epistemológicos e metodológicos, apresenta-se a visão das alternativas para seu desenvolvimento em cursos de 
pós-graduação. Em cursos de doutorado, recomenda-se a oferta de uma disciplina obrigatória de Epistemologia da Administração com o objetivo de desenvolver as duas primeiras competências. Em cursos de mestrado, se a ele vinculado também há um curso de doutorado, a disciplina pode ser ofertada como eletiva. Ressalta-se que aqui a não obrigatoriedade da disciplina de epistemologia em cursos de mestrado não exime o projeto do curso em incluir as competências e temas respectivos em disciplinas obrigatórias de métodos de pesquisa.

Todas as outras competências podem ser desenvolvidas em disciplinas relacionadas à metodologia da pesquisa. Entretanto a proposta deste estudo envolve a segmentação dos temas em três eixos de formação metodológica: o primeiro abrange aspectos relacionados a métodos de pesquisa, tipos de pesquisa, mensuração e design de pesquisa numa perspectiva mais ampla, questões ligadas à ética na pesquisa, validade e confiabilidade, além de reflexões sobre a prática da pesquisa a partir de relatos de experiências. O segundo eixo de formação abrange temas ligados à pesquisa quantitativa em administração, com ênfase nas especificidades do design de uma pesquisa quantitativa, teste de hipóteses e amostragem, pesquisa de levantamento, experimentos e principalmente análise de dados. O terceiro eixo contempla aspectos ligados à pesquisa qualitativa na administração, com foco na discussão sobre a natureza e as especificidades da pesquisa qualitativa, os métodos de investigação qualitativa, as estratégicas de coleta e análise de material empírico e o uso de softwares na análise de dados.

Considera-se que a melhor forma de desenvolver as competências no mestrado seria por meio da oferta de três disciplinas obrigatórias, que seriam: fundamentos da pesquisa em Administração (com ênfase nos conteúdos de epistemologia, e sobre a condição e a caracterização do campo de pesquisa realmente praticado); planejamento da pesquisa qualitativa; e planejamento da pesquisa quantitativa. Entende-se, portanto, haver uma falha na construção atual de boa parte dos programas brasileiros, que tornaram obrigatória a disciplina de Métodos quantitativos, quase sempre referente ao conteúdo de Estatística básica. A despeito da relevância do conteúdo, entende-se que conteúdos de análise somente têm sentido se forem posteriores e contextualizados dentro do planejamento da pesquisa quantitativa; adicionalmente, somente se vê sentido em se ter uma disciplina focada em 'métodos quantitativos' como obrigatória se houvesse uma disciplina também obrigatória de 'métodos qualitativos'. Por esse entendimento, a disciplina de Métodos quantitativos precisa ser deslocada para a condição de eletiva e ser ofertada para ser cursada por estudantes que forem 
desenvolver pesquisas de base quantitativa em suas pesquisas.

No doutorado, como já exposto, entende-se ser apropriada a existência de três disciplinas obrigatórias, a saber: Epistemologia, Métodos de Pesquisa Quantitativa e Métodos de Pesquisa Qualitativa (estas duas últimas com foco em métodos de análise de dados). Também aqui se sinaliza, na visão dos autores deste artigo, um viés na construção atual dos cursos de doutorado de boa parte dos programas brasileiros, que tornaram obrigatória a disciplina de Análise Multivariada. Essa disciplina de Métodos de Pesquisa Quantitativa permite contemplar não apenas um conjunto específico de pesquisa estatística (como são os métodos multivariados), ela abre também possibilidade de inserção de conteúdos mais utilizados no mainstream de pesquisa (como métodos não paramétricos ou os métodos experimentais; esta última se tornou, nos últimos anos, a principal referência de pesquisa em Marketing, por exemplo, e que, em geral, é uma técnica especializada e preponderantemente bivariada).

A forma como as competências serão desenvolvidas deve também fazer parte da discussão dos docentes do curso no momento de operacionalização das atividades das disciplinas e não se pode colocar a responsabilidade nos professores responsáveis pelas disciplinas específicas de epistemologia e de métodos de pesquisa, uma vez que vários professores de disciplinas adotam o artigo teórico-empírico como um dos instrumentos de avaliação, o que mantém articulação com os saberes da prática da pesquisa, abordada mais adiante neste artigo.

Os temas relacionados ao primeiro eixo de formação apresentado têm como objetivo levar o aluno a desenvolver as competências ligadas a conhecimentos mais amplos do universo da pesquisa, da conduta do pesquisador e também das dificuldades e peculiaridade inerentes ao processo de pesquisa. Já os temas relacionados ao segundo e terceiro eixo de formação são mais específicos e aplicados a dois caminhos diferentes para conduzir uma pesquisa: um quantitativo e outro qualitativo. A operacionalização dos temas no ambiente de aprendizagem dos alunos da pós-graduação podem incorporar ainda atividades vivenciais da prática da pesquisa, sobretudo no processo de coleta e análise de material empírico. Os laboratórios de prática de pesquisa poderiam ser incorporados como estratégia de ensino orientada para a ação, o que pode contribuir para tornar o processo de aprendizagem mais significativo.

Villardi e Vergara (2011) realizaram um estudo com o objetivo examinar a prática de 
ensino-aprendizagem durante e após o processo de aprender a pesquisar de alguns alunos do curso de mestrado que estavam cursando a disciplina de metodologia da pesquisa. Os resultados do estudo trouxeram implicações práticas no processo de ensino-aprendizagem da disciplina metodologia da pesquisa, sobretudo pela possiblidade de criar um ambiente de aprendizagem que oportunize a aprendizagem experiencial e a criação de um ambiente para o diálogo e a reflexão pública para compartilhar experiências. Destacam ainda a importância do professor no desenvolvimento da competência da formação docente ligada à pesquisa e o estabelecimento de atividades para estimular a reflexão dos alunos, considerando-se o tempo da prática reflexiva. A recomendação dos autores para os gestores dos cursos é que eles devem "considerar que a aprendizagem vivencial é interdisciplinar e complexa por natureza; no processo de aprendizagem é necessário considerar um tempo para reflexão pública dos alunos e tempo para vivenciar, além do tempo para estudar" (VILLARDI; VERGARA, 2011, p. 812).

\subsection{Saberes teóricos}

Os saberes teóricos envolvem conhecimentos substantivos do campo de Administração, sejam de natureza geral ou de natureza específica de concentração ou de linhas de pesquisa. Como bem defende Masetto (1998, p. 19), "a docência em nível de ensino superior exige do candidato, antes de tudo, que ele seja competente em uma determinada área de conhecimento" (ver ainda MASETTO, 2003). Neste caso de estudo, a área é a Administração.

Na prática corrente no Brasil, é comum existir em cada programa uma disciplina de conteúdo geral na forma da disciplina de Teoria das Organizações, e as demais são variadas e desenvolvidas segundo o dimensionamento corrente da formação em Administração na graduação (com os focos funcionais de Administração de Marketing, Administração da Produção...) ou segundo as especialidades de linhas, em que as definições são feitas ora por uma concepção de linha, ora pela disponibilidade de competências do corpo docente que integram cada linha.

Não há dúvidas de que essa dimensão deve ocupar um espaço substancial do esforço de formação, uma vez que o docente o será sempre em um campo específico do conhecimento em Administração. Isto é especialmente verdadeiro no mestrado, por sua formação prioritária para o ensino. E mesmo os cursos de doutorado precisam debater o conhecimento avançado e 
o estado da arte mais atual para o desenvolvimento posterior de pesquisas de alto impacto.

Em termos de competências a serem desenvolvidas, entende-se que o melhor dimensionamento é aquele em que os conhecimentos gerais são desenvolvidos em dois níveis: no curso de mestrado, o foco preferencial deve ser em tópicos básicos de Administração geral, de Teoria das organizações e da Administração e, principalmente, nos conteúdos associados à área de concentração; já para o curso de doutorado a formação geral deve ser definida pelos tópicos gerais e mais avançados da área de concentração de cada programa.

Com essa ideia, sinaliza-se o entendimento aqui de que há um vício no modelo atual de formação dos mestrados (e em menor escala dos doutorados). De fato, a grande maioria dos programas tem a disciplina de Teoria das organizações como obrigatória, ao que parece, sob o pressuposto de que a Teoria das Organizações representa, no todo, os conhecimentos gerais de Administração. Essa prática tem dois problemas: primeiro, não é verdade que a Teoria das Organizações seja uma disciplina que incorpore o conhecimento geral de Administração (salvo nos casos mais complicados ainda em que se tenta entender que Teoria das Organizações equivale a Teorias da Administração, o que é facilmente refutado pela tradição de pesquisa e de discussão em cada nível especializado deste campo); segundo, e considerado mais problemático aqui, é o fato de esta disciplina não trazer, necessariamente, a discussão sobre o conhecimento central das áreas de concentração dos programas.

Pela base de conhecimentos gerais, as competências específicas a serem formadas seriam (as duas primeiras no curso de mestrado, e a última no curso de doutorado):

a) desenvolver conhecimentos do contexto histórico, epistemológico, econômico e social do conhecimento acadêmico de Administração, para viabilizar uma visão da Administração em geral;

b) desenvolver uma discussão sobre os tópicos teóricos centrais da área de concentração do programa, para viabilizar uma visão global da concentração do programa;

c) desenvolver uma discussão complementar e dos tópicos de fronteira em termos de pesquisa sobre os tópicos teóricos da área de concentração do programa, para viabilizar uma visão avançada da concentração do programa.

A materialização da formação nessa competência no nível geral pode ocorrer por meio de ao menos uma disciplina obrigatória no mestrado e outra obrigatória no doutorado, que podem ter seu momento de execução sempre no primeiro ano de curso. Relativo aos conhecimentos específicos, estes são definidos pelos blocos centrais de cada linha existente e 
com vinculação à concentração do programa. Por exemplo, um aluno que se vincula a uma linha de Marketing deverá cursar disciplinas de formação nessa área. No entendimento dos autores deste artigo, as linhas de um programa mais sólido devem ser definidas pelo conhecimento necessário para o futuro acadêmico da área e não em função do que os docentes daquela linha podem ou se consideram mais seguros em ministrar. Isso significa que a forma de materialização desse nível de conhecimentos seja decorrente da concepção de linha e da contribuição para a concentração do programa e que a construção seja feita levando em conta o mainstream nacional e internacional de desenvolvimento de conhecimentos associados à linha.

Levando-se em conta a ideia aqui defendida, as disciplinas de conhecimentos específicos precisam considerar tanto o contexto de pesquisa (na qual os futuros docentes desenvolverão seus trabalhos de pesquisa) quanto o conhecimento necessário para o exercício futuro de atividades de ensino.

\subsection{Saberes da prática de ensino}

Os saberes da prática de ensino estão ligados à educação em Administração e devem preparar o pós-graduando para o planejamento e a ação docente em sala de aula. Conforme já indicado acima, no processo de formação docente a prática de ensino talvez seja a menos valorizada pelos Cursos de Pós-graduação stricto sensu. Entretanto, considerando-se que a ação docente em sala de aula é uma das dimensões fundamentais na formação profissional, o desenvolvimento de competências para o ensino é estratégico para o desenvolvimento do país, uma vez que a qualificação do docente tem reflexo na formação do profissional da graduação e da pós-graduação.

Ressalta-se ainda que o professor universitário atua em sistema complexo, seja em função dos vários tipos de instituições de ensino ou da necessidade de lidar com um perfil de aluno que demanda não só uma preparação didático-pedagógica, como também uma visão mais humanista e orientada para os valores sociais. Além disso, o docente deve estar preparado para difundir estratégias de ensino em ação (SILVA et al., 2012; LIMA; SILVA, 2012) que estimulem o pensamento reflexivo dos alunos (ARAÚJO et al., 2012) e a vivência de experiências profissionais e sociais como determinante na aprendizagem do profissional 
em processo de formação (SANTOS; SILVA, 2012). As competências específicas relacionadas aos saberes da prática de ensino são as seguintes:

a) conhecer a origem e as bases reguladoras do ensino em Administração;

b) planejar com eficiência as atividades de ensino relacionadas a uma disciplina específica;

c) utilizar estratégias de ensino coerentes com as competências a serem desenvolvidas pelo discente;

d) definir critérios e instrumentos de avaliação da aprendizagem dos alunos para as diferentes competências desenvolvidas;

e) utilizar os recursos da tecnologia da informação na ação docente;

f) compreender a dinâmica do processo de gestão do ensino em estreita relação com o perfil do futuro profissional: projeto pedagógico de curso, matriz curricular, atividades curriculares e de interesse curricular, projetos de integração multidisciplinar e interdisciplinar.

O desenvolvimento dos saberes da prática de ensino no curso de pós-graduação abrangem atividades centradas na ação formal, por meio da oferta de disciplinas como Prática de Ensino em Administração, Metodologia do Ensino Superior, Casos para Ensino em Administração, dentre outras, além de atividades práticas por meio dos estágios de docência. Nas disciplinas, os docentes podem institucionalizar um processo de aprendizagem experiencial e mediado pela ação. Entende-se que as disciplinas precisam ser vivenciais, de modo que o pós-graduando tenha a oportunidade de participar ativamente e de refletir sobre a prática docente. Em uma disciplina de casos para ensino em Administração, por exemplo, podem-se levar os alunos a vivenciarem o processo de análise de um caso na sala de aula para, em seguida, aplicarem um caso em uma turma da graduação e realizar um relatório da atividade que possibilite um processo de reflexão sobre a ação (SCHÖN, 2000). Também podem desenvolver uma atividade prática de elaboração de um caso para ensino sobre um tema relacionado à linha de pesquisa do curso a que está vinculado. Na visão dos autores deste artigo, a oferta das disciplinas deve ocorrer no primeiro ano para que, no segundo ano, o mestrando/doutorando vivencie a prática de ensino por meio do estágio docente, que foi formalizado pela CAPES em 1999 e é obrigatório para os alunos bolsistas.

Em uma disciplina formal do nível inicial (como as de Prática de Ensino em Administração ou de Metodologia do Ensino Superior), além de o professor abordar aspectos 
envolvendo o planejamento e a ação docente, tem-se um momento relevante para se discutirem questões institucionais envolvendo o sistema de educação superior, procedimentos e normas acadêmicas, elaboração de projetos pedagógicos de cursos, questões ligadas ao relacionamento professor-aluno, entre outros. Pela relevância desses temas para os futuros docentes, entende-se que a disciplina precisa ser obrigatória nos programas.

Em relação ao estágio de docência, nesta proposta de itinerários, este deve ser uma atividade curricular obrigatória para todos os alunos dos cursos, uma vez que não são apenas os estudantes bolsistas que exercerão o ofício de professor. Considera-se que este deve ser obrigatório inclusive para os alunos do curso de doutorado e propõe-se que nesse nível seja operacionalizado em dois estágios: o primeiro com ênfase no ensino em sala de aula; e o segundo envolvendo outras atividades relacionadas à ação do docente doutor, como orientação de trabalhos de conclusão de curso e de iniciação científica, avaliação de artigos e da sistemática de captação e gestão de recursos para pesquisa. Um segundo estágio docência para os alunos do doutorado pode promover a articulação entre os saberes que integram esta proposta, levando-se em conta a atuação do profissional com a titulação que está para conseguir

Além de disciplinas e do estágio de docência, outras ações que podem contribuir no desenvolvimento das competências vinculadas à prática de ensino envolvem a oferta de cursos e seminários extracurriculares para os alunos ou ainda o planejamento e a oferta de minicursos direcionados para alunos da graduação ministrados por alunos da pós-graduação. Tais ações fomentariam o desenvolvimento de competências em ação voltadas para o ensino sob a supervisão do professor orientador ou de um professor ou supervisor acadêmico do curso.

Um desafio interessante, que se opta por não desenvolver aqui, deixando-se a reflexão para outros estudos e propostas, consiste em criar a figura do professor orientador para o ensino, que se complementaria com o orientador para a pesquisa (cf. MADHAVARAM; LAVERIE, 2010). Na prática corrente, o processo de orientação está centrado quase que exclusivamente na pesquisa do estudante, o que é de fato necessário. A figura do orientador para o ensino seria uma ação a ser empreendida pelo orientador de pesquisa (que seria uma espécie de orientador acadêmico e que apoiaria o estudante tanto nas atividades de ensino quanto nas atividades de pesquisa) ou outros docentes com quem o estudante desenvolveria as atividades de formação de conteúdos pedagógicos e de estágio de docência. 


\subsection{Saberes de produção escrita}

Os saberes de produção escrita concernem ao exercício da produção de gêneros textuais acadêmicos. A necessidade de inserção nos programas de pós-graduação de um bloco de ações de formação para a produção de gêneros acadêmicos é facilmente justificada, pois não são raros os casos em que o estudante tem evidentes dificuldades de materialização, em texto, do que pensa, do que sabe ou do que encontrou em esforços de pesquisa. Com efeito, quando um estudante é selecionado para um curso de pós-graduação, parece já ser admitido por hipótese que tem todas as condições para escrever textos científicos com a fluência necessária. No entanto, a experiência dos autores atesta o contrário, sendo evidenciados diversos problemas desde os primeiros movimentos e demandas de produção, e não são raros relatos de decepção de professores quanto leem os trabalhos ou artigos de final de disciplinas. Portanto, a fragilidade dessa crença se dilui na prática, o que parece indicar a real necessidade de um foco específico por parte dos programas nesses saberes. Ademais, são diversos os gêneros escritos de que um acadêmico precisa se apropriar, sendo destacados os seguintes: resumos, resenhas, position papers, artigos, dissertações, teses, casos para ensino, notas de ensino, projetos de pesquisa etc. (cf. SWALES, 1990; MOTTA-ROTH; HENDGES, 2010). Cada um desses gêneros tem sua caracterização temática, estilística e composicional própria, o que requer do acadêmico conhecimento e habilidade diferenciada de produção.

Em uma visão global do que é requerido, interpreta-se que os saberes de produção escrita se realizam na aquisição de competências e habilidades na produção de diferentes gêneros acadêmicos e na realização de prática mais específicas associadas ao seguinte:

a) apropriar-se dos aspectos formais e funcionais dos gêneros mais demandados no campo (por exemplo, a condução das informações em uma introdução é bem distinta das considerações finais de uma tese);

b) conhecer os fundamentos e especificações de normalização;

c) conhecer estratégias de argumentação presentes em alguns gêneros acadêmicos;

d) realizar, de forma pragmática, a produção do texto em si.

Embora seja uma necessidade bem evidente, não se têm relatos de programas de pósgraduação em Administração que já tenham desenvolvido orientações mais sólidas para o desenvolvimento dessas competências. Do ponto de vista de atividades acadêmicas voltadas à 
produção escrita, os programas podem institucionalizar uma disciplina de Leitura e Produção de Gêneros Acadêmicos, não necessariamente obrigatória, ou desenvolver seminários especiais ou laboratórios de produção escrita, de normalização etc. Além disso, acredita-se que as disciplinas de seminários de dissertação ou de tese, que são recorrentes nos programas de pós-graduação brasileiros, poderiam ser destinadas a desenvolver essa competência, em complemento ou em substituição ao que se faz na maioria das vezes (na experiência dos autores deste artigo, os focos são mais centrados na análise de pesquisas, delimitações de temas e discussão de estudos em andamento).

\subsection{Saberes da prática da pesquisa}

Os saberes da prática da pesquisa são caracterizados pela ação do pós-graduando na elaboração do trabalho final do curso e na produção escrita em diferentes gêneros acadêmicos. A motivação para essa dimensão de formação é simples: a pesquisa é uma experiência que agrega grande parte do que os estudantes construíram em termos de conhecimento de conteúdo ou de capacidade de produção escrita, além de ser uma contribuição ao desenvolvimento do conhecimento científico.

A competência de prática de pesquisa é, em geral, muito bem desenvolvida na formação de mestres e doutores, e parece adequado seu desenvolvimento como feito atualmente por meio de produção de artigos em disciplinas ou grupos de pesquisa e principalmente por meio da dissertação de mestrado ou tese de doutorado. Pelo modelo atual, os saberes de prática de pesquisa se realizam em diferentes níveis de exigência a depender da orientação epistemológica ou de preferência metodológica de estudantes ou de seus orientadores. De um modo geral, as competências mais específicas desse nível seriam as seguintes:

a) construir uma revisão de literatura sobre um tema de forma mais direta (como nos artigos) ou com maior aprofundamento (como nas dissertações e teses);

b) analisar e elaborar um design de pesquisa empírica;

c) organizar e coordenar esforços para conduzir uma pesquisa de campo, tanto para pesquisas de natureza qualitativa quanto quantitativa;

d) conduzir o processo de análise de dados de campo, podendo incluir a operacionalização de ferramentas computacionais de análise de dados e discussão de 
resultados confrontando teoria e dados de campo;

e) ajustar o conteúdo do trabalho final para submissão do resultado da pesquisa a um periódico, a um evento, ou a uma banca examinadora.

O dimensionamento dessa competência tem de levar em conta o nível de formação do estudante. Assim, a competência de prática de pesquisa no mestrado precisa ser recolocada no mesmo nível de importância que as competências acima, principalmente porque o futuro mestre não terá na pesquisa sua carreira central (uma vez que sua vocação maior deve ser o ensino). Por essa razão, a dissertação de mestrado precisa ser pensada como uma experiência de pesquisa que consolida e viabiliza a aquisição dessa competência, mas não a finalidade central do processo de formação de mestres. Já no doutorado, a prática de pesquisa precisa ser expandida em termos de demanda para rigor e relevância, tendo em vista que os futuros doutores serão, em tese, os pesquisadores legitimados como geradores de conhecimento em Administração, relevantes para a sociedade ou as unidades organizacionais nas quais a pesquisa terá maior potencial de aperfeiçoamento da prática gerencial.

Para qualquer um dos níveis, são os professores orientadores os principais agentes de condução dessa competência. Em menor escala, tem-se seu desenvolvimento realizado em parceria ou sob demanda de outros docentes na construção de artigos para disciplinas, grupos ou projetos de pesquisa.

\section{CONSIDERAÇÕES FINAIS}

Neste artigo discutiu-se o processo de formação de docentes em Administração, o que se faz preponderantemente a respeito de cursos de mestrado acadêmico e de doutorado, e buscou-se ainda apresentar uma proposta de formação baseada no conceito de competências, com a indicação de quais são, no entendimento dos autores, as mais fundamentais na formação dos docentes, e de como essas competências poderiam ser desenvolvidas, a partir dos esforços de formação empreendidos dos programas de pós-graduação. Reconhece-se o conteúdo polêmico de algumas das indicações aqui apresentadas, porém acredita-se que a discussão tem impactos teóricos e práticos.

Do ponto de vista teórico, o artigo se insere em um conjunto de outras discussões já empreendidas sobre formação docente (em geral, e em Administração em particular), e, por 
sua construção vinculada à experiência vivida além de sua orientação prescritiva, entende-se que o estudo contribui para o debate e outras construções teóricas de pesquisadores com interesse neste tema.

Já do ponto de vista prático, considera-se que o estudo tem o potencial de servir de base de reflexão para docentes e líderes do processo de formação de docentes em cursos de pós-graduação em Administração, servindo, senão como a base de construção de projetos de programa, ao menos como uma proposta fundamentada na teoria e na prática vivenciada.

Ressalta-se que, apesar da indicação de saberes sugerir algumas disciplinas específicas que subsidiem o desenvolvimento de competências docentes, não se teve a intenção de padronizar a formação, mas de exemplificar como viabilizar sua introdução. A existência de áreas de concentração e de linhas de pesquisa específicas podem ensejar disciplinas obrigatórias alinhadas a subáreas do conhecimento da administração, o que é legítimo e deve ser estimulado. A recomendação, aqui, partiu de uma concepção geral, mas não definidora, de modo que outras opções podem emergir do debate contextualizado sobre cada uma das competências.

Embora o estudo tenha sido construído com base em uma literatura de referência em termos de formação docente e levando em conta as práticas vivenciadas e refletidas pelos autores, há naturalmente limitações. A principal delas é a própria forma resumida como cada competência foi apresentada. Embora seja obrigação dos autores serem claros e fluentes no espaço disponível (isto é competência de produção escrita que se relata), o que foi exposto requer maiores desdobramentos, explicitações e aperfeiçoamentos, e fica colocado como desafio para estudos futuros.

Entre os desafios apresentados neste artigo, destaca-se que a efetividade da implantação de projeto de formação no mestrado ou no doutorado depende da institucionalização de um conjunto de atos regulatórios para estabelecer parâmetros de referência que balizem as ações internas de formação e garantam sua legitimação institucional interna e externa. Em verdade, a regulamentação formal é condição de base para implementação do modelo, sendo requerido que os programas desenvolvam regulamentações específicas dimensionando a forma como cada competência deverá se desenvolver (por exemplo, as resoluções de estágio de docência podem ser adaptadas para contemplar elementos mais gerais de regramento da formação da competência docente).

A discussão empreendida neste artigo também resgata uma reflexão sobre a regulação 
do processo de avaliação da pós-graduação. Apesar de a CAPES ter sinalizado a valorização da formação docente em Administração em 2008, por meio do edital Pró-Administração, tornou-se necessário estabelecerem-se ações de discussão e reflexão com o objetivo de fortalecer sua missão institucional na busca da excelência acadêmica na formação de mestres e doutores. Isto se faz, entende-se, com a definição de maior valorização dos resultados de formação para a docência nos critérios de avaliação da CAPES.

Outra reflexão importante envolve o papel dos professores na articulação entre os saberes necessários à formação docente. Será que os professores dos Programas dispõem de conhecimento, tempo e de recursos para introduzirem estratégias de ensino orientadas para a ação e para o desenvolvimento de competências discentes? Não seria o momento de os programas institucionalizarem fóruns acadêmicos destinados a uma autorreflexão e uma reflexão coletiva para delimitar itinerários específicos e mais alinhados conceitualmente à proposta de um curso ou programa? A observação exploratória e a experiência sinalizam que boa parte dos professores de pós-graduação opta pela formação para a pesquisa, em boa medida porque, dentre os critérios de sua avaliação, os mais delicados são aqueles relacionados à publicação (o debate sobre o produtivismo já está bem avançado no Brasil, e foi evitado aqui). Nesse contexto, a força dos apelos de coordenadores e pares para que os professores se engajem em mais esta atividade de formação é insuficiente, o que sugere novamente a necessidade de uma regulamentação interna e da requisição externa (da CAPES, por exemplo). Este é seguramente o maior dos desafios para implementação deste modelo, e deixam-se, como recomendação de outras reflexões, a experimentação e a avaliação alternativas para superação desse desafio.

Um desdobramento importante deste artigo envolve a realização de uma pesquisa empírica com coordenadores, professores e discentes de cursos de pós-graduação da área de Administração para subsidiar o aprimoramento desta proposta e também apresentar um panorama sobre a percepção desses agentes em torno da relevância e da presença dos saberes necessários à formação docente. Também uma reflexão sobre itinerários formativos para cursos de mestrado na modalidade profissional é um desdobramento que merece destaque para futuros estudos, tendo em vista a consolidação desses cursos na pós-graduação brasileira. 


\section{REFERÊNCIAS}

ARAÚJO, G. D.; SILVA, A. B.; BISPO, A. C. K. A.; LIMA, T. B. Desenvolvimento do Pensamento Reflexivo no Curso de Administração. In: XXXVI ENCONTRO DA ANPAD, Anais... 2012, v. 1. p. 1-16, 2012.

BRANDÃO, H. P. Mapeamento de Competências: métodos, técnicas e aplicações em Gestão de Pessoas. São Paulo: Atlas, 2012.

CAPES. Relatório de Avaliação 2010-2012 - Trienal 2013, da área de Administração, Ciências Contábeis e Turismo. Disponível em: http://www.avaliacaotrienal2013.capes.gov.br/relatorios-de-avaliacao . Acesso em: 10 mar. 2014.

CIRANI, C. B. S.; SILVA, H. H. M.; CAMPANARIO, M. A. A Evolução do Ensino da Pósgraduação Estrito Senso em Administração no Brasil. Revista de Administração Contemporânea - RAC, Rio de Janeiro, v. 16, n. 6, p. 765-783, nov./dez. 2012.

CUNHA, P. R.; HEINZMANN, L. M.; SILVEIRA, A. Epistemologia: um primeiro olhar sobre o ensino nos programas de doutorado em Administração e Ciências Contábeis e a produção científica no brasil. In: XIII SEMEAD - Seminários de Administração. Anais... São Paulo, USP, 2010, v. 1, p. 1-17, 2010.

HAIR JR., J. F.; BABIN, B.; MONEY, A. H.; SAMOUEL, P. Fundamentos de Métodos de Pesquisa em Administração. Porto Alegre: Bookman, 2005.

LE BOTERF, G. Desenvolvendo competências dos profissionais. 3. ed. Porto Alegre: Artmed, 2003.

LIMA, M. C.; RIEGEL, V. A Formação Docente nos Cursos de Pós-Graduação em Administração - a gênese de uma experiência. In: II ENCONTRO DE ENSINO E PESQUISA EM ADMINISTRAÇÃO E CONTABILIDADE, Anais... João Pessoa, ANPAD, 2011, v. 1, p. 1-17, 2011.

LIMA, T. B.; SILVA, A. B. Difusão das Estratégias de Ensino balizadas pela Aprendizagem em ação no Curso de Administração. In: XXXVI ENCONTRO DA ANPAD, Rio de Janeiro, Anais... 2012, v. 1, p. 1-16, 2012.

MADHAVARAM, S.; LAVERIE, D. A. Developing pedagogical competence: issues and implications for marketing education. Journal of Marketing Education, v. 32, n. 2, p. 197$213,2010$.

MASETTO, M. T. Competência Pedagógica do Professor Universitário. São Paulo: Summus, 2003.

MASETTO, M. T. Professor universitário: um profissional da educação na atividade docente. In. MASETTO, M. T. (org.). Docência na Universidade. Campinas: Papirus, 1998.

MERRIAM, S. B.; BROCKETT, R. G. The profession and practice of adult learning: an introduction. San Francisco: Jossey-Bass, 2007.

MOTTA-ROTH, D.; HENDGES, Graciela H. Produção Textual na Universidade. São Paulo: Parábola Editorial, 2010.

OLIVEIRA, M. C. S.; MELO, M. C. O. L.; OLIVEIRA, M. H.; PAIVA, K. C. M. A 
Influência da "Vivência Docente" na Formação e Desenvolvimento de Competências Profissionais Docentes: uma percepção de mestrandos em administração. In: II ENCONTRO DE ENSINO E PESQUISA EM ADMINISTRAÇÃO E CONTABILIDADE, Anais... Curitiba, ANPAD, 2009, v. 1, p. 1-17, 2009.

PACHANE, G. G; PEREIRA, E. M. de. A importância da formação didático-pedagógica e construção de um novo perfil para docentes universitários In: Revista Iberoamericana de Educación, v. 33, n. 4, p. 1-13, jul.2004.

PEREIRA, B. B. Estatística: a tecnologia da ciência. Boletim da Associação Brasileira de Estatística, ano XIII, n. 37, $2^{\circ}$ quadrimestre, p. 27-35, 1997.

PERRENOUD, P. Novas competências para ensino. Porto Alegre: Artes Médicas, 2000.

REY, B. As competências transversais em questão. Porto Alegre: Artes Médicas, 2002.

SANTOS, G. T.; SILVA, A. B. O Papel da Experiência na Aprendizagem de Alunos do Curso de Administração. In: XXXVI ENCONTRO DA ANPAD, Anais... Rio de Janeiro, ANPAD, 2012, v. 1, p. 1-17, 2012.

SCHÖN, D. A. Educando o profissional reflexivo: um novo design para o ensino e a aprendizagem. Porto Alegre: Artes Médicas Sul, 2000.

SILVA, A. B.; LIMA, T. B.; SONAGLIO, A. L. B.; GODOI, C. K.; Dimensões de um Sistema de Aprendizagem em Ação para o Ensino em Gestão. RAEP - Administração: Ensino e Pesquisa, v.13, n.1, p. 9-41, 2012.

SWALES, J. M. Genre Analysis: English in academic and research settings. Cambridge: Cambridge University Press, 1990.

TARDIFF, M.; LESSARD, C. O trabalho docente: elementos para uma teoria da docência como profissão de interações humanas. 3. ed. Petrópolis: Vozes, 2007. p. 15-54.

VILLARDI, B. Q.; VERGARA, S. C. Implicações da Aprendizagem Experiencial e da Reflexão Pública para o Ensino de Pesquisa Qualitativa e a Formação de Mestres em Administração. Revista de Administração Contemporânea - RAC, Curitiba, v. 15, n. 5, p. 794-814, set./out. 2011. 